\title{
INFLUENCE OF THE ORGANOPHILISATION PROCESS ON PROPERTIES OF THE BENTONITE FILLER AND MECHANICAL PROPERTIES OF THE CLAY/EPOXY NANOCOMPOSITES
}

In this comparative study, the influence of the organophilisation process on the properties of resulting organobentonite fillers and their capability to improve the mechanical properties of clay/polymer nanocomposites were investigated. The organobentonites were obtained by activation with the use of two organic quaternary ammonium salts (QAS) with alkyl chains of significantly different lengths. The organophilisation resulted in an increase in the interlayer space of clays, which was confirmed by XRD analysis. The obtained organofillers were used to produce nanoclay/epoxy resin composites and the effects of alkyl chain length on the resulting properties of composites were compared based on the examination of mechanical behaviour and morphology, and a composite filled with the non organophilised bentonite was used as a reference material. It was demonstrated that the organophilisation process using distearyldimethyl ammonium chloride salt with a longer alkyl chain (C18-C20) created a more superior conditions for the compatibility of nanofiller with a polymer matrix, resulting in a $25 \%$ increase in the bending strength of the epoxy composite material filled with $3 \% \mathrm{wt}$ of the organophilised bentonite, comparing to neat epoxy.

Keywords: bentonite, nanocomposites, organophilisation, mechanical properties

\section{Introduction}

Polymer-based nanocomposites filled with nanoclay particles have attracted significant attention, as they provide substantial improvements in physical, mechanical, thermal, electrical and barrier properties over conventional polymer composites [1-7]. When it comes to mechanical properties, nanoclays are more efficient than classical fillers in strengthening the polymer matrices, especially when they are added in small amounts. Volume fractions of the clay fillers as low as 1-3\% can result in tremendous increase in both stiffness and strength while exerting no influence on the overall density of material [8-11].

Smectites are among the most frequently used nanoclay fillers due to their great capacity for cation exchange, swelling, high platelet aspect ratio and ease of surface modification. However, smectite fillers are initially hydrophilic in their nature, resulting in incompatibility with most polymeric materials, which makes the smectites ineffective for the modification of relatively hydrophobic compounds [12]. There are a few methods for the conversion of a clay surface from hydrophilic to hydrophobic, and the complete process is known as organic modification or organophilisation. Proper organophilisation is a key step for successful intercalation and exfoliation of clay particles in most polymeric matrices and the most popular methods of carrying it out are based on cation exchange using amino acids $[13,14]$, long-chain amines or quaternary organic ammonium salts [15], or organic tetra phosphonium. The resulting materials are known as organoclays, and the products of interactions between clay minerals and organic compounds have found an important application in polymer nanocomposites [16-18].

The purpose of this study was to investigate the compatibility of the thermoset bisphenolic epoxy resin with organobentonite fillers obtained by exchanging inorganic cations of the clay with organic ammonium ions. Two different organoclays, obtained through the organophilisation process using quaternary ammonium salts (QAS) with distinctly different chain lengths, were used. Composite materials filled with organoclays were prepared using a standard vacuum casting process. Finally, the mechanical behaviour and morphology of the composites, as well as the influence of subsequent fillers on these properties, were evaluated.

\section{Experimental}

\subsection{Materials}

The bentonite clay (Jelšový Potok, Slovak Republic), originally hydrophilic in nature and thus theoretically useless for the reinforcement of polymeric matrices, was used as the reference filler for the reinforcement of the epoxy resin. The other two organobentonite fillers were produced based on the same bentonite substrate but treated with two different quaternary ammonium salts (QAS) with a different alkyl chain length (see Table 1) for which the general formula is given below (1):

\footnotetext{
* AGH UNIVERSITY OF SCIENCE AND TECHNOLOGY, FACULTY OF MATERIALS SCIENCE AND CERAMICS, AL. MICKIEWICZA 30, 30-059 KRAKÓW, POLAND

** AGH UNIVERSITY OF SCIENCE AND TECHNOLOGY, FACULTY OF ENERGY AND FUELS, AL. MICKIEWICZA 30, 30-059 KRAKÓW, POLAND

\# Corresponding author: kmita@agh.edu.pl
} 
Description of materials used in the study

\begin{tabular}{|c|c|c|c|}
\hline \hline \multirow{2}{*}{ Material } & Description & \multicolumn{2}{|c|}{ Activating compound } \\
\cline { 3 - 4 } & Neat epoxy resin & Chemical name & Alkyl chain \\
\hline ER $/ 3 \%$ BE & Epoxy filled with the reference bentonite filler & - & - \\
\hline ER/3\%OBE-1 & $\begin{array}{c}\text { Epoxy filled with bentonite modified with QA } \\
\text { Salt Type 1 }\end{array}$ & alkyltrimethyl ammonium chloride & from C11 to C18 \\
\hline ER/3\%OBE-2 & $\begin{array}{c}\text { Epoxy filled with bentonite modified with QA } \\
\text { Salt Type 2 }\end{array}$ & $\begin{array}{c}\text { distearyldimethyl ammonium } \\
\text { chloride }\end{array}$ & from C18 to C20 \\
\hline
\end{tabular}

\section{$\left[\mathrm{R}_{1} \mathrm{R}_{2} \mathrm{R}_{3}\right] \mathrm{N}^{+} \mathrm{R}_{4} \mathrm{X}^{-}$}

where: $\mathrm{R}_{4}$-hydrophobic alkyl chain, $\mathrm{R}_{1}, \mathrm{R}_{2}, \mathrm{R}_{3}$ - alkyl groups, $\mathrm{X}^{-}$- chloride anion [19].

The organophilisation process was carried out to change the surface properties of the base bentonite from hydrophilic to hydrophobic, in order to produce and enhance both dispersion and compatibility of the clay particles within the polymer matrix [20]. The base bentonite, after initial cleaning using the sedimentation process, was activated in the slurry with magnetic stirring at around $70^{\circ} \mathrm{C}$. Following the activation process, the powder was rinsed to the point of extinction of the chlorine ion reaction; then the organobentonites obtained in this procedure were dried and milled.

The obtained powders were used as fillers for typical bicomponent bisphenolic DGEBA epoxy resin (CY 225/HY 925, produced by Huntsman), commonly used for various industrial applications. For all of the materials, fillers were added in an amount of $3 \% \mathrm{wt}$, then pre-mixed with the hardener and subsequently with the rest of the components. The samples were produced by a vacuum casting process and cured for 8 $\mathrm{h}$ at $140^{\circ} \mathrm{C}$, according to the curing procedure provided by the manufacturer. Solid neat epoxy resin samples were also manufactured and the description of all materials is provided in Table 1.

\subsection{Methods}

The non-modified bentonite (BE) as well as the organobentonites OBE-1 and OBE-2 were characterised by X-ray diffraction analysis (XRD) and the parameter $d_{001}$, describing the interplanar distance in montmorillonite, was calculated in order to evaluate the effectiveness of the intercalation process. The measurements were performed in the range $3<2 \theta<70$ with $\mathrm{Cu} \mathrm{K} \alpha$ radiation using a PANalytical Empyrean diffractometer with a step size of 0.008 degrees (total time: about $4 \mathrm{~h}$ ). The analysis was focused on the range $3<2 \theta<10$, where the most characteristic diffraction peak assigned to the (001) basal plane of montmorillonite appears.

The morphology of the fillers, non-activated bentonite as well as the organobentonites, was characterised by transmission electron microscopy (JEOL JEM-1011 (TEM)) as well as by scanning electron microscopy (FEI Nova NanoSEM 200, (SEM)). Particle size distribution was evaluated by the dynamic light scattering method (Zetasizer Nano ZS by Malvern Instruments) in water suspension at $25^{\circ} \mathrm{C}$. Prior to measurement, the powders were dispersed in water with a 100
W ultrasonic disintegrator, type UD-20 (Techpan), for $0.5 \mathrm{~h}$. The fracture surfaces after mechanical tests were observed with the use of scanning electron microscopy (using the same Nova NanoSEM 200 device).

Flexural modulus, flexural strength and strain at break, were determined according to the ISO 178 standard using a Zwick Roell ZO.5 testing machine. The specimens, in rectangular form $(80 \times 10 \times 4 \mathrm{~mm})$, were cut out mechanically according to the procedure described by the same standard. Span support was adjusted at $64 \mathrm{~mm}(16 \times$ thickness $)$ and a test speed giving a flexural strain rate as near as possible to $1 \%$ per minute was implemented.

\section{Results and discussion}

\subsection{XRD analysis}

Organophylisation was confirmed through XRD analysis based on the results presented in Table 2 . It is clearly visible that the characteristic peak of montmorillonite at $6.9^{\circ}$ of $2 \theta$ in the non-organophilised bentonite changes its position, moving towards lower angle values, and which basal indicates that the use of ammonium salts leads to a shift in the peak for the (001) plane and consequently to an increase in the value of the interplanar spacing, $d_{001}=1.28 \mathrm{~nm}$, of the starting BE powder to the value of $1.88 \mathrm{~nm}$ for the OBE-1 clay activated with alkyltrimethyl ammonium chloride and to $2.32 \mathrm{~nm}$ for the OBE-2 clay activated with distearyldimethyl ammonium chloride. This confirms the occurrence of intercalation chains of the ammonium salt between layers of montmorillonite.

TABLE 2

$d_{001}$ basal spacing for BE, OBE-1 and OBE-2 filler powders

\begin{tabular}{|c|c|c|}
\hline \hline Powder & $2 \theta\left(^{\circ}\right)$ & d-spacing $(\mathrm{nm})$ \\
\hline BE & 6.9 & 1.28 \\
\hline OBE-1 & 4.7 & 1.88 \\
\hline OBE-2 & 3.8 & 2.32 \\
\hline
\end{tabular}

\subsection{Morphology}

TEM and SEM micrographs of the reference material as well as of organoclay fillers are presented in Fig. 1 and Fig. 2. Grain size distribution provides additional information about the microstructure of fillers before and after organophilisation (Fig. 3). 

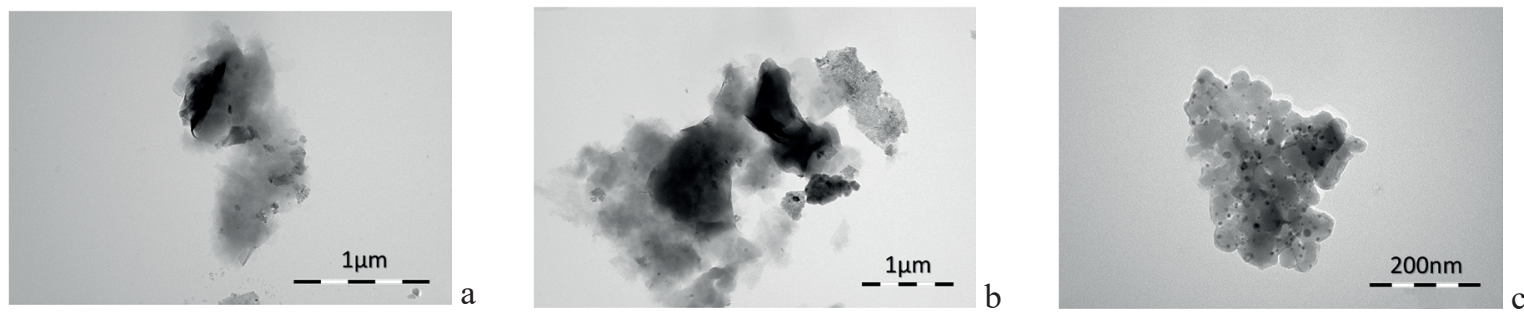

Fig. 1. TEM characterisation of the bentonite fillers: a) reference bentonite (BE) filler, b) OBE-1 organophilised bentonite and c) OBE-2 organophilised bentonite
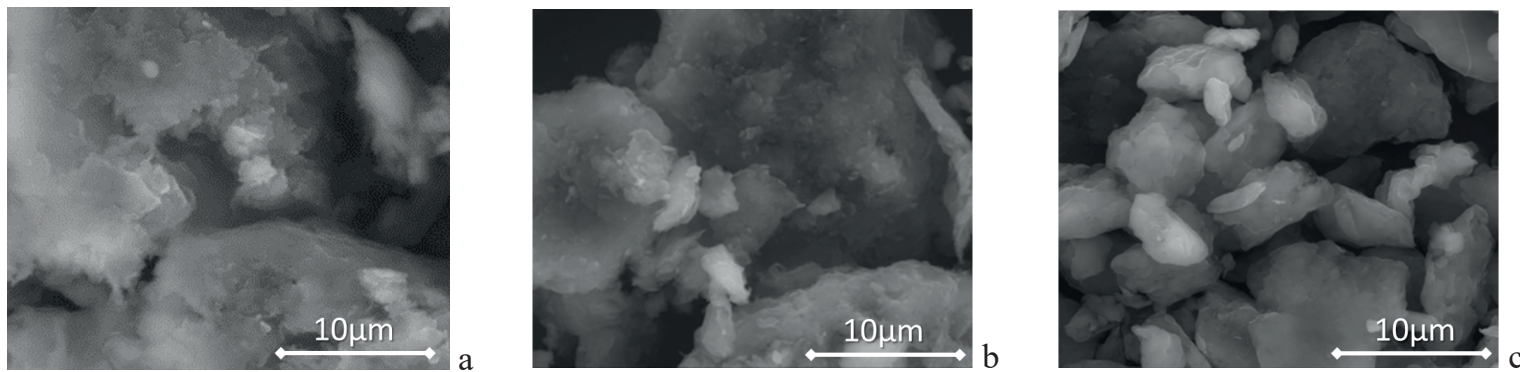

Fig. 2. SEM characterisation of the bentonite fillers: a) reference bentonite (BE) filler, b) OBE-1 organophilised bentonite and c) OBE-2 organophilised bentonite
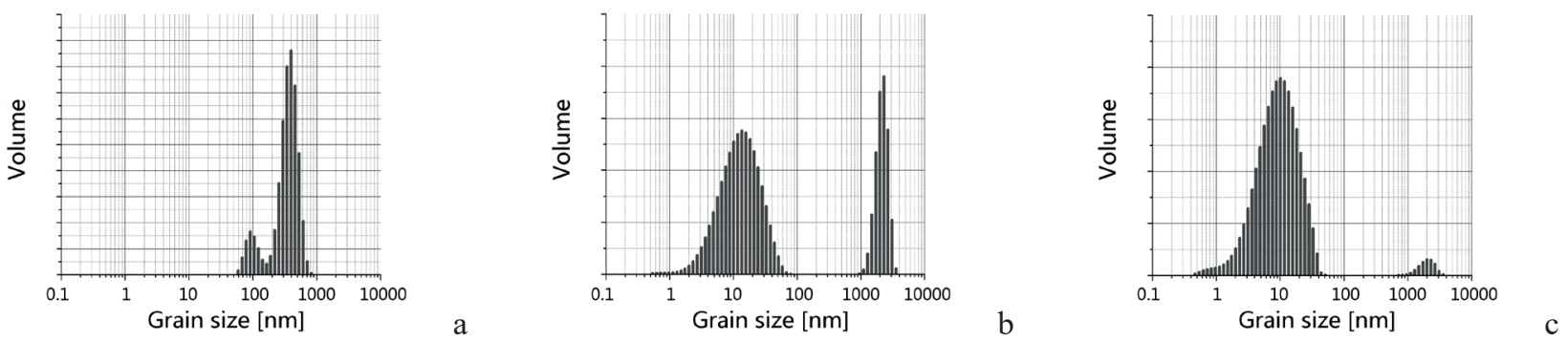

Fig. 3. Grain size distribution of the fillers: a) reference bentonite (BE), b) OBE-1 organophilised bentonite and c) OBE-2 organophilised bentonite

It is seen from the TEM and SEM images, as well as from the grain size distribution measurements, that organophilisation affects clay powders morhhology. The average grain size (around $400 \mathrm{~nm}$ ) characteristic for non-organophilised bentonite powder (Fig. 3a) decreases significantly in the case of organophilised nanoclays. This denotes microstructural changes connected with breaking down the agglomerates (agglomerated grains) which were present in the base powder. After organophilisation, the aggregates are still visible in the OBE-1 powder, but disappear in the OBE-2 powder (Fig. 3c). This suggests weaker grain-to-grain attractive interactions in the organophilised agglomerates due to the steric effect caused by the alkyl chains adsorbed on the grain surface.

This leads to the conclusion, that organophilisation performed with the use of the OBE-2 quaternary ammonium salt with a longer alkyl chain (C18-C20) produces much better conditions for a nanofiller for compatibility with the polymer matrix. These properties have been found to be less optimal for organophilisation carried out using the OBE-1 ammonium salt with a shorter alkyl chain (C11-C18), whereby the agglomerates are still visible in the grain distribution (Fig. 3b) and the OBE-1 powder is not as well dispersed (Figs. 1 and 2).

\subsection{Mechanical properties}

The primary goal of this research was to evaluate the influence of the nanoclay organophilisation process on the mechanical properties of composites reinforced with organoclay fillers. Mechanical properties of the clay-filled epoxy composite materials were determined in bending static tests according to the ISO 178 standard; the results are presented in Table 3.

Mechanical properties of tested clay-filled epoxy matrix materials

\begin{tabular}{|c|c|c|c|c|c|c|}
\hline \hline Materials & \multicolumn{2}{|c|}{$\mathrm{E}[\mathrm{GPa}]$} & \multicolumn{2}{c|}{$\sigma_{\text {break (flexural) }}[\mathrm{MPa}]$} & \multicolumn{2}{c|}{$\varepsilon_{\text {break (flexural) }}[\%]$} \\
\hline $\mathrm{ER}$ & $3.26 \pm 0.08$ & reference & $80.81 \pm 4.16$ & reference & $8.78 \pm 0.56$ & reference \\
\hline $\mathrm{ER} / 3 \% \mathrm{BE}$ & $3.12 \pm 0.17$ & $-4.3 \%$ & $87.84 \pm 5.73$ & $8.7 \%$ & $3.02 \pm 0.04$ & $-65.6 \%$ \\
\hline $\mathrm{ER} / 3 \% \mathrm{OBE}-1$ & $3.39 \pm 0.16$ & $4.0 \%$ & $91.59 \pm 3.64$ & $13.3 \%$ & $2.87 \pm 0.03$ & $-67.3 \%$ \\
\hline $\mathrm{ER} / 3 \% \mathrm{OBE}-2$ & $3.52 \pm 0.06$ & $8.0 \%$ & $101.38 \pm 2.99$ & $25.5 \%$ & $3.21 \pm 0.13$ & $-63.4 \%$ \\
\hline
\end{tabular}


The greatest increase in flexural stress at break and stiffness was obtained for epoxy composite material filled with bentonite after organophilisation with a quaternary ammonium salt (OBE-2) with a relatively long molecular chain. The values of flexural modulus and stress at break are $3.5 \mathrm{GPa}$ and 101.4 MPa, respectively, which are higher by $8 \%$ and $25.5 \%$ compared to the corresponding neat epoxy properties. For nanocomposites filled with bentonite after organophilisation with the quaternary ammonium salt (ER/3\%OBE-1) with a shorter molecular chain, the reinforcement effect is not as strong as for the ER/3\%OBE-2 material. The values of flexural modulus and stress at break are $3.4 \mathrm{GPa}$ and $91.6 \mathrm{MPa}$ respectively, which are higher by $4.0 \%$ and $13.3 \%$ compared to the neat epoxy. However, even in this case, reinforcement is more effective than for nonorganophilised bentonite filler, which provides an increase in flexural strength of less than $10.0 \%$ and more than a 4.0 $\%$ decrease in stiffness. Thus, it can be concluded finally that changes of filler properties from hydrophobic to hydrophilic are crucial to the efficient improvement of mechanical properties, and that organophilisation reduces the energy of the clay and improves its compatibility with organic polymers.

The stress-strain curves for neat epoxy and nanocomposites filled with various bentonites under flexural loading are shown in Fig. 4, and it is shown that the addition of clay to epoxy has a considerable effect on stress-strain behavior. It can be clearly seen that both flexural modulus and flexural stress at break increase for nanocomposites filled with bentonites organophilised with quaternary ammonium salts (ER/3\%OBE-1 and $\mathrm{ER} / 3 \% \mathrm{OBE}-2)$. On the other hand, the nanocomposite filled with non-organophilised bentonite (ER/3\%BE) shows only a slight reinforcing effect on flexural stress at break and even a decrease in flexural modulus value (only the initial slope of the stress-strain curve for neat epoxy is shown in the figure).

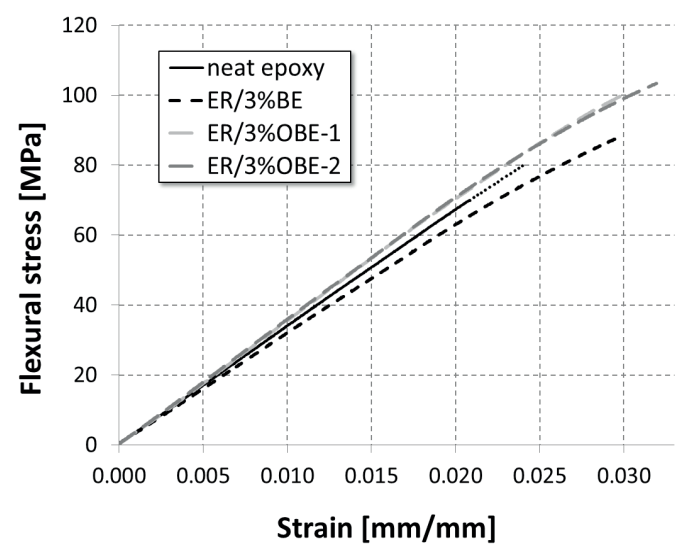

Fig. 4. Comparison of stress-strain relationships for neat epoxy and bentonite-filled nanocomposites

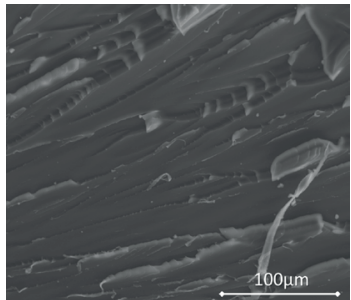

a) ER sample

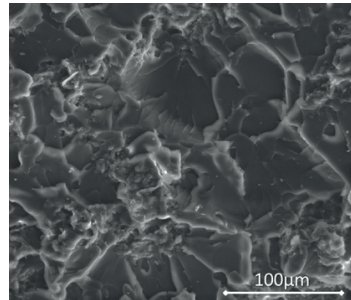

b) $\mathrm{ER} / 3 \% \mathrm{BE}$
It can be also seen from the results that the strain at break for organoclay-filled materials is much lower than for neat epoxy material. Strain to break for ER/3\%OBE-2 nanocomposite is $3.2 \%$, denoting a $63.4 \%$ decrease comparing to nonreinforced epoxy. For ER/3\%OBE-1 material these values are $2.9 \%$ and $67.3 \%$, respectively, for $\mathrm{ER} / 3 \% \mathrm{BE}$ material, 3.0 $\%$ and $65.6 \%$ respectively. This leads to the conclusion that reinforcement in nanocomposites results in the limitation of undesirable extensive changes in elongation and strain of the materials. Consequently, increased resistance to creep can be expected, even for volume fractions of filler as small as $3 \% \mathrm{wt}$.

\subsection{Microstructure observations}

SEM observations were also made for all fracture surfaces obtained following mechanical tests in order to estimate the influence of different fillers on the fracture mechanisms of materials. The results of the SEM observations are shown in Fig. 5.

It is seen that the fracture for neat epoxy is rather smooth, suggesting rupture and catastrophic failure under the bending load. For fractures reported for composites filled with reference bentonite (non-organophilised bentonite), the surfaces are more developed and complex, which may indicate that more energy is needed for decohesion and break compared to the neat epoxy resin. Even more complex surfaces with superior development can be observed for the composites filled with organobentonites; however, no significant differences are present between the images of composites filled with organobentonites modified with alkyltrimethyl ammonium chloride and with distearyldimethyl ammonium chloride salts.

\section{Conclusions}

Results indicate that epoxy matrix composite materials filled with both organophilised and non-modified bentonites possess superior mechanical properties compared to neat epoxy resin. The addition of $3 \% \mathrm{wt}$ of filler to the polymeric matrix causes a significant increase in strength at break, while stiffness is almost unaffected and strain at break becomes acceptably low. However, it has been shown that organophilisation of bentonite clay using quaternary ammonium salts improves the compatibility of the fillers with an epoxy matrix and, consequently, the mechanical properties of the organoclayfilled epoxy composites, especially when the organophilisation process was carried out using distearyldimethyl ammonium chloride salt with a longer alkyl chain (C18-C20).

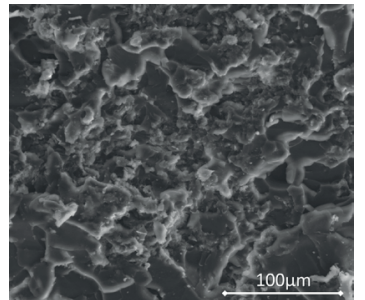

c) $\mathrm{ER} / 3 \% \mathrm{OBE}-1$

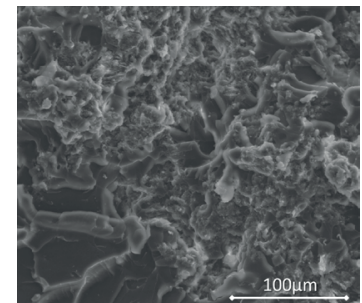

d) $\mathrm{ER} / 3 \% \mathrm{OBE}-2$

Fig. 5. SEM observations of the fracture surfaces after mechanical tests 
The effectiveness of organophilisation was confirmed in XRD analysis by a more significantly shift of the (001) peak for the clay activated with organic quaternary ammonium salt with alkyl chains of significantly higher lengths, which resulted in a more distinct increase in the interlayer spaces in the bentonite. As result, the greatest increase in bending strength was found for epoxy composite material filled with bentonite organophilised with distearyldimethyl ammonium chloride salt with relatively longer alkyl chains.

The obtained results lead to the conclusion that the tested organobentonite materials can be successfully used as fillers for conventional epoxy resin matrix composites.

\section{REFERENCES}

[1] M. Alexandre, P. Dubois, Mater. Sci. Eng. 28 (1-2), 1-63 (2000).

[2] N. Gupta, T.C. Lin, M. Shapiro, J. Mat. 59, 61-65 (2007).

[3] J.H. Park, S.C. Jana, Polym. 44 (7), 2091-2100 (2003).

[4] E.P. Giannelis, R. Krishnamoorti, E. Manias, Adv. Polym. Sci. 138, 107-147 (1999).

[5] D.P. Park, J.H. Sung, S.T. Lim, H.J. Choi, M.S. Jhon, J. Mater. Sci. Lett. 22, 1299-1302 (2003).

[6] B.T. Marouf, R. Bagheri, R.A. Pearson, Int. J. Mod. Phys. B 22, 3247-3253 (2008).

[7] J.J. Luo, I.M. Daniel, Com. Sci. Technol. 63, 1607-1616
(2003).

[8] A. Yasmin, J.J. Luo, J.L. Abot, I.M. Daniel, Com. Sci. Technol. 66, 2415-2422 (2006).

[9] P.C. LeBaron, Z. Wang, T.J. Pinnavaia, Appl. Clay Sci. 15, 1129 (1999).

[10] A. Rapacz-Kmita, E. Stodolak-Zych, M. Dudek, B. Szaraniec, A. Rozycka, M. Mosialek, L. Mandecka-Kamien, Physicochem. Prob. Min. Proc. 49 (1), 91-99 (2013).

[11] T. Choudhury, N.M. Misra, Bull. Mat. Sci. 33, 165-168 (2010).

[12] D. Schmidt, D. Shah, E.P. Giannelis, Curr. Opin. Solid State Mater. Sci. 6, 205-212 (2002)

[13] A. Usaki, M. Kawasumi, Y. Kojima, A. Okada, J. Mater. Res. 8, 1174-1178 (1993).

[14] A. Usaki, Y. Kojima, M. Kawasumi, A. Okada, Y. Fukushima, T. Kurauchi, O. Kamigaito, J. Mater. Res. 8, 1179-1184 (1993).

[15] H. Haerudin, A.W. Pramono, D.S. Kusuma, A. Jenie, N.H. Voelcker, C. Gibson, Int. J. Technol. 1, 65-73 (2010).

[16] I.B. Paiva, A.R. Moralez, F.R.F. Diaz, Appl. Clay Sci. 42, 8-24 (2008).

[17] J. Makarian, Plast. Addit. Compd. 7, 18-21 (2005).

[18] S.S. Ray, M. Okamoto, Prog. Polym. Sci. 28, 1539-1641 (2003).

[19] [20] M. Oleksy, M. Heneczkowski, Polimery 53, 219-223 (2008).

[20] A.D. McNaught, A. Wilkinson, Compendium of Chemical Terminology ("Gold Book"), $2^{\text {nd }}$ edition, 1997 Blackwell Scientific Publications, Oksford. 
